Chapman University

Chapman University Digital Commons

Philosophy Faculty Articles and Research

Science and Technology Faculty Articles and

Research

\title{
7-3-2014
}

\section{Immigration and Self-Determination}

Bas van der Vossen

Follow this and additional works at: https://digitalcommons.chapman.edu/philosophy_articles

Part of the Ethics and Political Philosophy Commons 


\section{Immigration and Self-Determination}

\section{Comments}

This is a pre-copy-editing, author-produced PDF of an article accepted for publication in Politics, Philosophy \& Economics, volume 14, issue 3, in 2015 following peer review. The definitive publisherauthenticated version is available online at https://doi.org/10.1177/1470594X14533167.

\section{Copyright}

The author 


\title{
Immigration and Self-Determination
}

\section{Bas van der Vossen}

University of North Carolina Greensboro, USA

\begin{abstract}
This article asks whether states have a right to close their borders because of their right to selfdetermination, as proposed recently by Christopher Wellman, Michael Walzer, and others. It asks the fundamental question whether self-determination can, in even its most unrestricted form, support the exclusion of immigrants. I argue that the answer is no. To show this, I construct three different ways in which one might use the idea of self-determination to justify immigration restrictions, and show that each of these arguments fails. My conclusion is that the nature and value of self-determination has to do with the conditions of genuine selfgovernment, not membership of political society. Consequently, the demand for open borders is fully consistent with respect for self-determination.
\end{abstract}

\section{Keywords}

Immigration, self-determination, borders, autonomy, Walzer, Wellman

\section{Introduction}

Recently a number of philosophers, most prominently Christopher Wellman (2011. Altman and Wellman 2011. Cole and Wellman 2011) and Michael Walzer (1984, 1993), have argued that 
states have the right to restrict immigration because of their rights to self-determination. ${ }^{1}$ The argument is straightforward: states (or the people organized in states) can enjoy a right to selfdetermination, ${ }^{2}$ a right that entitles them to determine their collective destiny. Immigration can significantly alter the nature of states and peoples. Therefore, the right to self-determination implies a right to control immigration. That is, just as voluntary groups have a right to freely decide whom to admit as new members, so too states have a right to decide whom to admit as immigrants.

The argument from self-determination seems to offer the most promising defense of a right of states to restrict immigration. It proceeds by few and very straightforward steps. And it appeals to widely accepted and seemingly plausible premises. Almost everyone agrees that states can enjoy some sort of right to self-determination. And almost everyone agrees that this right entitles them to determine their collective destiny. The argument from selfdetermination, if sound, would thus provide a strong foundation for the right to exclude immigrants. $^{3}$

This argument confronts those who, like me, are attracted to policies of open borders with a hard choice. We are confronted with three alternatives. Our first option, of course, is to admit defeat. Perhaps we should agree that states have the right to restrict immigration. Second, we might accept that if states had a right to self-determination, this right would also give them the right to exclude immigrants, but deny that states actually have the right to selfdetermination. Perhaps, contrary to what initially seemed very plausible, states turn out not to be the kinds of things that can be self-determining. On this response, we concede the theoretical force of Wellman and Walzer's view but avoid its practical implications for 
immigration policy by severing it from existing states. The third option would be to find some flaw in Wellman and Walzer's argument. If there is such a flaw, we can keep maintain the view that states can have rights to self-determination and our advocacy of open borders.

Whichever way we choose to go, then, the argument from self-determination promises to teach us something deep. The first option (accepting that states have the right to exclude immigrants) would constitute a major breakthrough in our thinking about immigration. The second option (denying that states can have the right to self-determination) would overturn what is commonly regarded as the keystone of international morality and international law. And the third option (demonstrating a flaw in the argument) would teach us something vitally important about the nature of self-determination.

A number of authors have responded to Wellman and Walzer's argument. Some object that it relies on an overly simple understanding of self-determination. Self-determination, it is said, is circumscribed by moral demands in ways that preclude any simple conclusions about closing borders (Blake 2012, pp. 751-2). Others deny the premise that states enjoy the kind of rights to self-determination that Wellman and Walzer have in mind. These authors typically point to the coercive nature of the state and argue that what is true of voluntary selfdetermining associations is not true of coercive states (Huemer 2010. Cole in Wellman and Cole 2011. Fine 2010).

Neither response is fully satisfactory to the defender of open borders. The former will disappoint those unwilling to accept a truncated view of freedom of association. The latter will not move anyone who thinks that states can enjoy a kind of self-determination. Moreover, both responses leave untouched Walzer and Wellman's most fundamental contention: that, at least 
in principle, self-determination implies a right to exclude immigrants. This essay challenges that fundamental point. It argues that the right to self-determination simply provides no support for the right to exclude. That is, even if we accept the robust rights to self-determination that Walzer and Wellman have in mind, and even if we accept that these rights apply to states, the argument for immigration restrictions still fails. ${ }^{4}$

The essay takes the following steps. Section 2 explicates the idea of self-determination, as suggested by its main defenders. Some may want to challenge parts of this account. I will not do so here because my goal is to show that even if we agree with Walzer and Wellman about the role and value of self-determination, their conclusions about immigration still do not follow. This is the purpose of sections 3 through 5 . Each of these inspects a different possible version of the argument from self-determination and shows that they provide no real support for a right to restrict immigration.

\section{Self-determination and autonomy}

The idea of self-determination plays a central role in much political and moral philosophy. It does so in the context of the freedom, moral status, and rights of individuals as well as the sovereignty, legitimacy, and rights of states. To better understand self-determination, in both its individual and communal forms, we can begin by looking at its value. Self-determination matters because of the importance of self-government or a self-directed life. A self-directed life is valuable, it is said, because it means our actions are in an important sense connected to our central values and desires. Self-government means that we live freely and independently. It is a life in which we are in control, living by our own lights. 
Self-determination thus epitomizes a valuable kind of freedom. In this way, the value of self-determination is closely related to the value of personal autonomy. Indeed, the two are often discussed side by side. Autonomous people are said to be self-governing or selflegislating. They endorse their actions, and impose whatever rules they live by on themselves. Autonomous persons are independent and free in much the same way that is central to selfdetermination. ${ }^{5}$

People are capable of autonomy or self-determination because they have the ability to choose for themselves how to act. As a broad generalization, let us say that an individual agent $\mathrm{P}$ is autonomous or self-determining when $\mathrm{P}^{\prime} \mathrm{s}$ actions are connected in the right way to those considered judgments, desires, or commitments that are truly P's own (to keep things manageable, I will henceforth call these P's values). The details of this broad formula are notoriously difficult to spell out with precision - something I will return to below - but for now let me say two things. First, as a reasonable approximation, we can say that P's actions are connected to his values in the right way when P's values form the basis of P's actions. And second, again approximately, P's values are P's own when they are not the result of autonomydebilitating external forces such as coercion. ${ }^{6}$

We can understand the value of group self-determination along analogous lines. Groups too are capable of independently choosing how to act, of free agency. And just as people can succeed in being self-determining or autonomous agents when they succeed in basing their actions on their own values and desires, so too, we might say, groups can succeed in being selfdetermining when they base their actions on their own collective or communal values. The free actions of groups might thus have a value similar to the actions of autonomous individuals. 
They are not just the causal results of the decisions they made. They are their actions. In this way, self-determination involves acting in a way that expresses the character of the agent. ${ }^{7}$

There is, however, an important ambiguity when we speak of group self-determination in this way. On the one hand, we might understand such self-determination as the groupversion of individual autonomy. Here groups a whole are seen as agents that are capable of acting freely and as having a right to self-determination (Altman and Wellman 2011, p. 6, Waldron, 2010). Let us call this the collective understanding of self-determination. On the other hand, we might see group self-determination as the extension of the individual autonomy of its members. Here, group self-determination is simply individual self-determination exercised collectively (Philpott 1995. Cf. Kershnar 2000). Call this the individualist understanding of selfdetermination.

The difference matters. The individualist understanding of self-determination makes sense in certain contexts. This is most clearly the case for voluntary groups. The members of such groups freely accept the terms of their membership by deciding to join and stay in them. Thus even those who oppose a certain decision freely accept being subjected to it by their continuing membership. As such, the members of voluntary groups can be said to collectively exercise their individual autonomy. And the group's decisions can be understood as autonomous because they are fully reducible to the autonomous decisions of its members. However, in the context of political states, appeals to the individualist understanding of self-determination suffer from serious problems. Most obviously, there is the fact that many of the members of states did not freely choose to join them. And when they disagree with decisions that are imposed on them (and backed up with force), they are not free to simply 
leave the state behind and continue to live their lives on their own terms. Here, no clear connection between group's actions and its members' autonomous wills may exist. As a result, it becomes difficult to maintain that the state is self-determining because its decisions are reducible to the autonomous decisions of its members. ${ }^{8}$

The collective understanding, by contrast, allows states to be self-determining under these conditions. For on this view, self-determination or autonomy consists in the group as a whole freely acting on the basis of its communal values. What matters here is for the group's actions to become connected to its communal values in the same way as an autonomous person's actions are connected to her values. This means that, insofar as they are capable, as groups, of free and self-directed action, even coercive institutions like the state can be selfdetermining.

It is not surprising, then, that the defenders of immigration controls on the basis of selfdetermination mostly appeal to the collective view of self-determination. Wellman is explicit in this regard. He rejects the individualist view, stressing that he understands "group autonomy to be something that can be exercised by a collective as a whole rather than individually by persons in a group." And that, for him, self-determination "exists when the group as a whole rather than the individuals within the group stands in the privileged position of dominion over the affairs of the group." (Wellman 2005, pp. 41 and 42 respectively. Emphasis in original) ${ }^{9}$

For these reasons, I shall henceforth understand, with a few explicitly noted exceptions, state self-determination in the collective sense. ${ }^{10}$

\section{Self-determination and immigration: the control of destiny argument}


Our question is whether the right to self-determination supports a right for states to control immigration. In this section and the next I discuss two relatively straightforward attempts to show that this is the case. In section 5 I proceed to investigate a subtler suggestion: that controlling immigration is bound up with the very nature of self-determination.

The first of these arguments goes as follows. The right to self-determination is a group's right to determine its destiny. And since new members bring along new views, desires, cultures, habits and norms, immigration into the community affects its destiny. Therefore, the right to self-determination implies the right to control immigration (cf. the "contract" argument in Kershnar 2000, pp. 142-5). Call this the control of destiny argument. We can summarize it as follows:

\section{The Control of Destiny Argument}

(1) States with a right to self-determination have the right to choose their political destiny

(2) Immigration affects the state's political destiny

(3) Therefore, states with a right to self-determination have the right to choose whether or not to allow immigration

The control of destiny argument fails because its first premise is false, and any way of making this premise true renders the argument question begging. To see why (1) is false, consider the analogous case of individual people's right to autonomy. Suppose Jim wants to work at Harvard University. Whether or not Harvard agrees to hire him deeply affects Jim's ability to live his life as he wants to. Yet this does not, of course, show that Jim has a right that Harvard hire him. 
The point here is simple enough. Our rights to autonomy protect us in a number of ways aimed at enabling us to determine our individual destinies. But it does not follow from this that everything that affects us is thereby protected by our autonomy-rights. Some things are (like the right to physical integrity or freedom), some things are not (like the right to work at Harvard).

The same is true for a group's right to self-determination. Self-determination does not entitle groups to have control over just anything that might affect their destiny. Suppose, for example, that Canada were to develop into an extremely desirable place to live for American citizens and opened its borders. And suppose that many Americans were to make use of the opportunities in Canada and left the US. This development would clearly affect the political destiny of the US. But it is also clear that US self-determination does not give it a right that Canada stop doing what it is doing. Just as in the case of persons, a group's right to selfdetermination protects it against only some things. ${ }^{11}$

What we need, then, is to distinguish between those things that affect the choices of agents in ways that are protected by their rights to autonomy or self-determination, and those that merely affect what we might call the background circumstances in which they make their choices. Thus premise (1) of the control of destiny argument should be replaced by something like the following:

(1') States with a right to self-determination have the right to choose their collective destiny within the background circumstances of choice

But if we accept ( $\left.1^{\prime}\right)$ then we must also, in order to make the argument valid, replace (2). This second premise should become something like: 
(2') Immigration affects a state's collective destiny and is not part of the state's background circumstances of choice

But this premise $\left(2^{\prime}\right)$ simply presupposes what is at stake. The very question we are asking is whether immigration falls within a state's right to self-determination or not. The more precise version of the control of destiny argument simply assumes that it does. As a result, the control of destiny argument fails. It either contains a premise (1) that is false, or it contains a premise $\left(2^{\prime}\right)$ that begs the question.

Note that this objection strikes against the control of destiny argument irrespective of whether the conception of self-determination that it invokes is individualist or collective. The point that rights to autonomy or self-determination must be exercised within the circumstances of choice applies in both instances.

\section{Self-determination and immigration: the freedom of association argument}

A second possible argument is suggested by Christopher Wellman (2008. Altman and Wellman 2011. Cole and Wellman 2011). It appeals to the idea that the right to self-determination implies a right to freedom of association. To respect the autonomy of individuals, the argument goes, we have to respect their rights of free association. Jim cannot alone decide that Jane is to marry him because Jane's right to autonomy gives her the right to make that call.

Something similar seems to be true for states. The US cannot unilaterally force Canada to enter into some treaty because Canada's right to self-determination gives it the right to choose whether or not it wishes to associate with the US in that manner. This would be for the 
US to force Canada in an unwanted political association that is ruled out by Canada's right to self-determination. ${ }^{12}$

Wellman suggests that we can apply this reasoning to immigration as well. Just like Canada has the right to reject associating with other groups or countries, like the US, so too Canada gets to choose whether or not to associate with other individuals, like immigrants. We can summarize this argument as follows:

\section{The Freedom of Association Argument}

(1) The right to self-determination of states gives them the right to choose with whom they wish to associate

(2) Immigrants associate with the state

(3) Therefore, states with a right to self-determination have a right to choose whether or not to allow immigration ${ }^{13}$

The problem with the freedom of association argument is that it equivocates between the collective and individualist understandings of self-determination identified above. If we understand the argument in the collective way, as Wellman says we should (see section 2 above), then premise (2) is false. But if we understand the argument in the individualist way, rendering premise (2) true, then premise (1) is false. Let me explain.

Consider first the freedom of association argument when consistently understood along collective lines. Can we say, on this reading, that premise (2) is true? The key question is whether immigrants seek to associate with the state as a collective entity. Compare this to the case in the example above of the US wishing to associate with Canada. There is a clear sense in which we can say that the US wishes to associate with Canada as a collective body. After all, the 
US is not looking to enter into a treaty with any individual person or Canadian citizen, but with the institution that represents the group of all Canadian citizens together. Should the US force Canada into this association, we can sensibly say it is doing something to the Canadian state understood as a collective unit, and thus that its self-determination is violated.

According to premise (2) of the (collective) freedom of association argument, immigrants seek to relate to Canada in the same way as the US. But this is plainly false: immigrants seek to interact with states in a decidedly different way. Immigrants do not seek to force an association onto the state (as a collective entity) for the simple reason that they do not seek to associate with it (as a collective) in the first place. Immigrants seek to join the state, to become an indistinguishable part of the collective body that constitutes the state as it is. And this is simply a different matter. ${ }^{14}$

We can see this by comparing the case of someone (call him Andy) successfully immigrating into a country like Canada, and Canada successfully joining the US in some treaty. Wellman thinks Andy and the US are in similarly placed with respect to Canada. But this is false. For while Andy becomes part of any association in which Canada (as a whole) enters, because has become a part of that Canadian state, the reverse is not true. The US does not also become party to all other Canadian associations. If Canada and Denmark enters into a mutual defense treaty, the US does not thereby become obligated to come to Denmark's defense. Andy, by contrast, does in just the same way as all citizens do.

Another way of seeing this is by comparing the ways in which the processes of entering into treaties and immigration are typically organized. Since entering into a treaty involves associating with groups as collective agents, treaties call for negotiations with state 
representatives, such as the foreign minister or secretary of state, are signed in name of the country as a whole, and so on. The same is not true in the case of immigration. Such negotiations would be beside the point since immigrants do not seek to associate with the collective body of the state, but to become constitutive elements of it. Thus, when immigration succeeds, it is unnatural to say that we are dealing with two separate entities, the group-agent Canada and the individual immigrant, now standing in a newly formed association. The natural thing to say is that we are now dealing with a single collective body that has gained a new member.

The upshot of this is that when immigrants join a state, they are not entering in an association with the state as a whole. Thus, premise (2) of the freedom of association, understood collectively, is false.

However, this is not to say that there can be no other ways in which immigration violates state self-determination. Two possible ways come to mind. First, it might be thought that unwanted immigration violates the collective self-determination of states because they change their make-up or nature in unwanted ways. I turn to this argument in the next section. Second, it might be pointed out that immigration does involve the creation of some new kind of association, only not one with the state as a collective entity but with its citizens. And indeed, this much seems true. By joining the political society that makes up the state, immigrants enter into a new political association with its citizens.

But this is to change the meaning of the idea of self-determination that is invoked by the freedom of association argument - away from the collective sense discussed so far, and toward the individualist sense of self-determination. So let us turn to that version. On an individualist 
understanding, premise (2) of the freedom of association becomes true. Immigrants enter into an association not with the state understood as a collective entity, but with all of its individual citizens. But now a different problem emerges. For while the individualist understanding of the argument renders premise (2) true, it also renders premise (1) false. That is, the individualist right to self-determination of states does not give them a right to decide whether or not to admit immigrants.

There are two reasons for this. First, as noted before, the individualist conception of self-determination ill fits the coercive nature of political states. Insofar as coercive states are self-determining, this is not because they are the result of individual citizens' collective exercises of autonomy. The individualist conception, in other words, does not seem consistent with the self-determination of actual states. As a result, it cannot support their right to selfdetermination either.

The second reason applies even if this first problem can be overcome. The individualist conception of self-determination fails to explain why the state is the unit with the right to exclude immigrants. If political groups organized in the state have this right because of their members' joint autonomous decisions, then presumably the same will be true of various subgroups within the state. Individualist freedom of association, that is, would seem to justify not only American exclusion of foreigners, but also Texan exclusion of Californians, Bostonian exclusion of New Yorkers, and really the exclusion of anyone from any part of the country, irrespective of whether they are citizens, alien residents, visitors, or whatever. ${ }^{15}$ But this is wildly different from both premise (1) and the conclusion of the freedom of association 
argument, which was supposed to establish a right for states or similar political entities to exclude immigrants in particular.

We can now see the problem with the freedom of association argument more clearly. ${ }^{16}$ For premise (1) to be true, we need to read the argument as relying on the collective conception of self-determination. But this renders premise (2) false. And for premise (2) to be true, we need to read the argument as relying on the individualist conception of selfdetermination. But this renders premise (1) false. As a result of this equivocation, the freedom of association argument is unsound. ${ }^{17}$

\section{Self-determination and immigration: the self-creation argument}

We have seen that a state's right to self-determination does not imply a right to control immigration for the reason that immigration affects the state's destiny. And we have seen that the right to self-determination does not imply a right to control immigration for the reason that it violates either the right to free association of the state or its citizens.

Why, then, might one think the right to self-determination includes the right to control immigration? Michael Walzer offers an interesting thought:

[T] he right to choose an admissions policy is more basic than any of these [other policies], for it is not merely a matter of acting in the world, exercising sovereignty, and pursuing national interests. At stake here is the shape of the community that acts in the world, exercises sovereignty, and so on. Admission and exclusion are at the core of communal independence. They suggest the deepest meaning of self-determination. 
Without them there could not be communities of character (Walzer 1984, pp. 61-2, italics in original. Cf. Walzer 1993)

Although I have ascribed the freedom of association argument to him, Wellman offers a similar suggestion about the connection between the admission policies of a group and its character. He writes (with Andrew Altman) that:

since a country's immigration policy affects who will share in controlling the country's future, it is a matter of considerable importance... [This] point[s] to a more general lesson. Because the members of a group can change, an important part of selfdetermination is having control over what the "self" is. (Altman and Wellman, p. 163) People who enter a community bring along their own values, desires, commitments, and culture. The addition of such new members changes the nature of the group. Some values and ideas that were not there before will be added. Others will become more pronounced or widely shared. Immigration can thus make a group not only take different actions going forward, it can deeply change its collective character. Walzer believes that groups have a right to control immigration because this is required for control over the group's character, and such control is an important part of self-determination. Self-determination, that is, includes not only determination by the self of its actions but also determination by the self of the self.

This idea has a direct analogy in the case of individual autonomy. Individuals too can have their character altered by the acquisition of new values and desires. And just as Walzer worries that the self-determination of groups is diminished when they lack control over how their membership is constituted - when unwanted immigrants get to join the state - so too one might worry that a person's autonomy is diminished when she has no control over her own 
character - when unwanted desires or values get to be added to one's person. Autonomous persons, that is, might have the control over their values and desires.

Let us call the exercise of such control over one's character self-creation. Following through on Walzer's suggestion, we can construct the following possible argument concerning immigration. Self-creation is an important part of self-determination. And if an agent has a right to self-determination, then the agent also has a right to self-creation. Since immigration necessarily changes the group's character, it can be consistent with self-creation only if it is the result of the group's free decisions to create itself in that way. Thus, the right to selfdetermination includes the right to control immigration.

\section{The Self-Creation Argument}

(1) Self-determination requires self-creation

(2) If $X$ requires $Y$, then the right to $X$ includes a right to $Y$

(3) Therefore, the right to self-determination includes a right to self-creation

(4) State self-creation requires control over immigration

(5) Therefore, a state's right to self-determination includes a right to restrict immigration The self-creation argument is the most original (and potentially deepest) version of the argument from self-determination. But it too suffers from problems. I here focus on the key claim that autonomy involves self-creation, stated in premise (1). There are three problems with this. The first and most serious problem, as explained in subsection $(A)$ below, is that we are not justified in believing that premise (1), on any formulation of that claim, is true. This problem is the most serious because it removes the possibility of relying on the self-creation argument in the debate on immigration. 
The other two problems arise once we temporarily set this problem aside in order to ask what would happen if the uncertainty about self-creation would be resolved in the direction the self-creation argument requires. I will discuss two possible interpretations of the idea of self-creation and show that neither supports Walzer's (and Wellman's) desired conclusions. The first interpretation, discussed in subsection (B), constructs premise (1) in a strong way. The second, discussed in subsection (C), constructs it in a more plausible and weaker form.

\section{(A) The problem of epistemic uncertainty}

The first problem to note is that we are not justified in believing that self-determination requires self-creation. We can see this by going back to the analogy with individual autonomy. The philosophical literature on autonomy is deeply divided over this issue. The question whether the causes of autonomous actions ultimately lie entirely within us, or whether autonomy is consistent with outside forces affecting one's choices, runs deep - it goes right to the heart of the debate between compatibilists and incompatibilists about free will. Some argue that outside influences on our actions need not impugn our autonomy. Here, roughly speaking, autonomy is said to depend on whether the agent's actions are appropriately connected to his values, but not on the agent's ability to determine these values and desires themselves. Others believe that autonomous agents need full control over their own nature or character, or the grounds of their actions, as well. Here autonomy is said, again roughly, to also depend on the way in which one has acquired the values on the basis of which one acts. Yet others think something in between these two extremes might be warranted.

These accounts all have some plausibility. Consider the following examples: ${ }^{18}$ 
CASE 1: Ann is singularly committed to philosophy and spends all her time reading and writing philosophy. Ann endorses this way of life. Ann's colleague Beth is committed to combining her work in philosophy with hiking and spending time with her friends. Beth too endorses this way of life. Both, assume, are autonomous. One day Charlie, who is Ann and Beth's unscrupulous Dean and wants Beth to become more like Ann, manages to brainwash Beth and turn her into the psychological twin of Ann. Beth now has the same values as Ann and, just like Ann, becomes a single-minded philosopher, something she (now) endorses.

It seems plausible that Charlie violated Beth's autonomy. But if that is plausible, then autonomy must have something to do with how we acquire our values and desires, not only with whether we endorse them or how they are connected to our actions once we have them. For given that Beth is Ann's psychological twin, and given that Ann is autonomous, such an explanation is necessary to show why Charlie violates Beth's autonomy.

So CASE 1 seems to tell in favor of a conception of autonomy that incorporates something like self-creation: autonomous agents determine their own values. And if that is right, then Beth must have freely chosen her values to be autonomous. But things are not that simple.

CASE 2: Dave is a dedicated parent. Dave can reflect on and endorses his parental values as both central to his personality and the kind of values he thinks people like him should have. Yet Dave never actively chose his parental values. They are the product of his upbringing, in which Dave's parents impressed on him the importance of good parenting. 
Dave acquired his parental values in a way that was beyond his control or choice. Yet since Dave seems to live by them in a way that we closely associate with autonomy it would be implausible to say Dave is non-autonomous. In this regard, Dave is like all of us. We acquire many desires in ways that seem to have very little to do with the kind of rational endorsement or choice involved in self-creation, and more with the context of our experiences, our environment, culture, and so on.

CASE 2 suggests that no acceptable theory of autonomy can require self-creation. Here it seems that what matters is that, going forward, we manage to connect our values (however these are acquired) to our actions in the right ways.

A lot depends, of course, on how the details of these cases are exactly spelled out. I return to this debate below. For now, a different point is more important. The literature on autonomy is deeply divided on just this issue. Plausible and coherent statements can be found of each of the (extreme) views - that autonomy requires full self-creation, and that autonomy requires no self-creation - as well as of intermediate views - that partial or qualified selfcreation matters. ${ }^{19}$ In light of this deep disagreement, any version of premise (1) of the selfcreation argument must rely on a very controversial view within a deeply contested debate.

This creates a serious problem of epistemic uncertainty. The issue of immigration is highly controversial, dividing both professional philosophers and the public at large. What we need in order to adjudicate this question, therefore, is an argument that appeals to premises that are not themselves equally controversial. Indeed, this seemed to be the main attraction of the argument from self-determination - it seemed to appeal to very uncontroversial premises, such as the value of state self-determination. But when we understand this value along the 
lines of self-creation, that appearance turns out to be deceiving. The value of self-creation is at least as controversial as restrictions to immigration. As a result, appeals to this (supposed) value cannot help support any conclusions about the issue of immigration. The argument from self-determination fails to give us a stable platform from which to make judgments about immigration.

This uncertainty cuts both ways, of course. No version of premise (1) of the self-creation argument can be invoked to justify conclusions about immigration. Thus, proponents of open borders are similarly unable appeal to views that deny that autonomy requires self-creation in support of their favored conclusions about open borders. But that is precisely the point. Given that we can neither point to premise (1) as clearly true nor point to it as clearly false, the argument from self-creation cannot further the debate about immigration.

(B) The strong version of self-creation is implausible

The first problem with the self-creation argument effectively takes it off the table as a viable move in the immigration debate. However, we might still ask what the implications for immigration would be if, one day, the debate about the nature and value of autonomy were to dissolve, and this would happen in favor of the view that autonomy requires self-creation. Would that mean the self-creation argument succeeds as a defense of immigration restrictions? Much here depends on how precisely we understand the relation between self-creation and self-determination expressed in premise (1). We have seen that Walzer (and Wellman) defend a nearly unlimited right to restrict immigrants in the name of self-determination. This suggests that we understand premise (1) in a very strong way, namely as suggesting that self- 
creation is a necessary condition for self-determination. After all, should self-determination require that agents have full control over their own make-up or character, then we can see why the right to self-determination would give states a nearly unlimited right to restrict immigration. Such control would then be necessary for the state to be a self-determining entity. Weaker interpretations of the importance of self-creation for self-determination will likely yield weaker conclusions about the importance of immigration for self-determination as well.

Another reason this strong interpretation is attractive is that the same intuition that motivates a concern for self-creation in the first place also motivates considering it essential to autonomy or self-determination. Autonomy or self-determination matters, we said, because there is value in the source of one's actions lying within the self. Self-determination, on this view, requires not just that we freely deliberate about what to do, but also that external forces do not determine our deliberations. Self-determination requires that the grounds of our choices (our values and character) do not come from the outside. Thus the absence of selfcreation seems to void self-determination. (For discussion, see Fischer 2011, pp. 163-4. See also Smilansky 2002, Kane 1998, and Strawson 2002.)

So let us first consider the self-creation argument on this strong reading of (1) - I discuss weaker versions next. There is an obvious problem with adopting this interpretation. For the view that self-creation is a necessary condition of self-determination corresponds to a view of autonomy that implies that most, or even all, existing agents are in fact non-autonomous. After all, as CASE 2 shows, all of our characters and actions are in part the product of non-chosen influences and forces. The strong view that self-creation is necessary for self-determination is 
therefore incompatible with the autonomy of actually existing agents. It is a demand to which we cannot live up. ${ }^{20}$

This is the second problem with the self-creation argument. Even if the uncertainty about autonomy would somehow dissolve, and even if this would support the view that selfdetermination requires self-creation, the strong version of premise (1) required for Walzer's (and Wellman's) strong conclusions about immigration threatens to defeat the possibility of actual states being self-determining. After all, just as individuals cannot live up to the demands of full self-creation, so too the character of states and groups is determined by influences not chosen by the state or group itself. Immigration is but a small element of this. Other examples are the daily births and deaths of members, the influence of outside cultures via mass media, the internet, and other modern means of communication, technological innovations, and so on. If strong self-creation is not in the cards for individuals, then a fortiori it is not in the cards for states and groups.

The strong version of premise (1) thus fails to help justify immigration restrictions. For while it would mean that states have a strong right to control immigration if they have a right to self-determination, it also means that no state in fact has a right to self-determination.

(C) More plausible and weaker forms of self-creation do not justify immigration restrictions This second problem is easily avoided of course. We might adopt a more plausible, and less demanding version of premise (1), one that expresses a more complicated relation between self-determination and self-creation, and is thus more likely to be relevant to the selfdetermination of actual states. 
A number of authors who have written on the issue of self-creation and personal autonomy have concluded that we should do just that. Joel Feinberg, for example, writes: [A] person must already possess at least a rudimentary character before he can hope to choose a new one... Always the self that contributes to the making of the newer self is the product both of outside influences and a still earlier self that was still less fully formed and fixed, and so on, all the way back to infancy... Self-creation in the authentic person must be a process of self-re-creation, rationally accommodating new experiences and old policies to make greater coherence and flexibility." (Feinberg 1989, pp. 33-5)

Feinberg is skeptical of the view that autonomy requires self-creation in the strong sense. Instead, he suggests, the kind of control we need to have over our selves takes a subtler form. The truth captured in CASE 1 does not require a view that renders self-determination or autonomy practically unattainable.

What should this subtler form of self-creation look like? For present purposes, the most promising attempt to spell out how the acquisition of values and desires constrains autonomy is probably the one provided by Alfred Mele (2001). According to Mele, what sets Beth apart from Dave in the two cases above is not that Beth, but not Dave, lacked control over the acquisition of her values. What matters for Mele, instead, are two facts: (a) whether the agent in question is practically able to "shed" his or her values, and (b) if the agent is practically unable to shed a value, whether that value was acquired in a way that "bypassed" the agent's normal mechanisms for shedding. Here, an agent is practically able to shed a value when under normal circumstances it is available to him or her to rationally evaluate and choose whether or not to 
keep, attenuate, or extinguish it. And one's ability to shed is bypassed when the agent is compelled by some external force that makes the agent practically unable to do this.

In the two cases above, both Dave and Beth acquire a value (good parenting and philosophy, respectively) without choosing so. And these values may become so central to their personalities that Dave and Beth cannot help but act on them. According to Mele, Dave and Beth can nonetheless be autonomous. If (a) both were able to rationally evaluate and choose whether or not to shed their values, they would still be autonomous. And (b) if they are not able to shed their values, their autonomy depends on whether these values were acquired in a way that bypassed their normal rational and evaluative faculties. Dave and Beth do not satisfy the first of these tests. However, the second test is satisfied by Dave, but not by Beth. After all, Beth acquired her value for philosophy as a result Charlie's bypassing her normal faculties for evaluating values. So Dave, but not Beth, can be autonomous. ${ }^{21}$

Mele's view fits the purposes of the self-creation argument well since it achieves two things at once: (a) it significantly constrains the manner in which autonomous agents acquire their values without freely choosing to do so, and (b) it does this in a way that is consistent with the autonomy of actually existing agents. Mele's view thus promises to render a version of premise (1) true without at the same time undercutting the possibility of state selfdetermination. ${ }^{22}$

Suppose, then, that the current uncertainty about self-creation were to be resolved in favor of Mele's view. What would this mean for immigration? Two points are important. First, for immigration to be in tension with self-determination, the entry of immigrants must be such as to bring about a change in the values of the community as a whole. Most forms of 
immigration do not have this effect. To change communal values more must happen than merely the entry into the community of a person with new ideas, expectations, and norms. What is needed is that this person's (or persons') ideas, expectations, and norms rise to the level of viable candidate principles on which the group as a whole might choose to act. They need to become prominent parts of the state's collective consciousness and deliberations, viable candidates for collective decision-making.

Second, a further necessary condition would be that when immigration does change the group's values in this way, the change must come about in a way that bypasses the group's normal processes of deliberation and decision-making. That is, immigration does not violate self-determination unless it effectively subverts the normal ways in which the group as a whole evaluates its various candidate values, and collectively decides whether or not to act on them. If throughout the process of immigration the community remains practically able to rationally evaluate the newly introduced values through its normal (democratic) decision-making processes, and choose whether or not to endorse or oppose them as grounds for action, then immigration can change the community's values and character without violating its selfdetermination.

This version of the self-creation argument thus suggests that there is a fundamental difference between two kinds of cases:

CASE 3: Elaine plays in a regular pickup soccer game. One day, and without asking, Elaine brings along Fred. The other players go along with playing their game, while Elaine gives up some of her playing minutes to Fred. After a few weeks, Fred has 
become a regular member of the group. While Fred likes playing soccer, he proposes to the group to alternate between soccer and baseball. After a while the others agree. Fred has joined the group without the group deciding to accept him. And Fred's joining introduced a new value (baseball) into the group, indeed one that lead to a change in the group's character and behavior. Yet clearly this did not harm the group's ability to be selfdetermining. As long as Fred's joining the group does not render it unable to make a genuine collective decision, nothing of importance about the group's collective self-determination seems to be lost.

But compare this to:

CASE 4: A group of like-minded people wants to start their ideal political society. They calculate that if enough of them move to a small island in the Caribbean, they can effectively take over its democratic political process. They move there and, using their overwhelming majority in the democratic process, turn the place into their ideal society. This, it seems, can involve a violation of self-determination. For a sudden influx of a homogenous group of immigrants could overwhelm the group's decision-making in ways that resemble an outside take-over. The likeminded people are aiming to bypass the current group's collective ability to evaluate its values. In such cases, immigration might suddenly make the group practically unable to genuinely evaluate and shed the new values that have been added. And thus, assuming the truth of Mele's view about autonomy, such cases of immigration could be inconsistent with the collective understanding of state self-determination.

Two things are worth noting here as further qualifications to this already tentative conclusion. First, since what matters to an agent's autonomy on this view is the practical ability 
to evaluate and shed certain values, it does not matter whether or not the agent ends up actually rejecting the newly added values. Thus, even when states and their decisions are profoundly changed by the influx of new members, self-determination need not be harmed. Second, Mele argues that an agent's practical inability to evaluate and shed values in fact does not entail that its autonomy or self-determination is compromised. If the inability is the result of the agent's prior autonomous decision, such inability remains consistent with autonomy. Applying this to the context of immigration, this means that even if a sudden influx of immigrants were to overwhelm a state's practical ability to evaluate and shed its new communal values, this need not threaten its self-determination. If the state or community previously chose to allow the influx in an exercise of self-determination, then sudden influxes of immigration that overwhelm its normal decision-making processes can be consistent with continued state self-determination.

With these qualifications in place, Mele's view offers the strongest possible case for immigration controls on the basis of self-determination. It shows that immigration can violate self-determination in circumstances like the ones sketched in CASE 4, and in such cases alone. Assuming, therefore, that we are justified in believing that the truth about autonomy and selfcreation is as Mele describes it (which we decidedly are not), this is the best we can do on behalf of the argument from self-determination. ${ }^{23}$

The most promising version of the self-creation argument thus ends up justifying border controls in a much more limited fashion than Walzer and Wellman suggest. One can only have a right to $\mathrm{X}$ in virtue of one's right to $\mathrm{Y}$ if having $\mathrm{X}$ in some way contributes or tends to contribute to $\mathrm{Y}$. That is, the right to self-determination supports a right to restrict immigration only insofar 
as the latter contributes to the achievement of the former - the latter is a function of the former. As a result, the right to self-determination supports the right to restrict immigration only insofar as such restrictions are necessary for states like the Caribbean island from CASE 4 to remain self-determining.

In most cases of actual immigration with which we are familiar, concerning large and diverse political groups that are organized in states, this would seem to require very large numbers of immigrants with a relatively homogenous background entering in relatively short periods of time. Unless immigration adds a lot of people, and unless the values of this immigrant population are not varied, the addition of people cannot change the character of the group in a way that overwhelms its normal decision-making processes. It seems then, that even if we grant something that is very controversial (i.e. the truth of Mele's view about autonomy) the self-creation argument at most offers states the right to resist the sudden influx of very large numbers of likeminded immigrants.

This point generalizes. Any view of self-creation that is consistent with the selfdetermination of actual agents will have to be significantly more complex than the kind of argument that, as we saw in subsection (B), is presupposed by Walzer and Wellman's conclusions. And this means it can support only conclusions about immigration that are much more complex as well. This, then, is the third conclusion: even on the strongest possible construal of the self-creation argument, the right to self-determination supports only a complex and highly limited right to restrict immigration in extreme circumstances. ${ }^{24}$

\section{Conclusion}


Wellman, Walzer, and others believe that self-determination gives states a nearly unlimited right to restrict immigration. They are wrong. With one highly uncertain and circumscribed exception, demands for open borders fully respect state self-determination.

The value of self-determination thus lies elsewhere. Self-determination concerns selfgovernment, a group freely acting on its communal values without wrongful interference. The nature of that group is always changing. It changes because new people are born, because of outside cultural influences, because of technological change. It also changes because of immigration.

One might nonetheless have worries about immigration, some of which seem related to self-determination. Perhaps immigration can put pressure on a country's commitment to democracy. Or perhaps communities have some other kind of interest in controlling their populations. Or perhaps immigration would lead to violations of political justice in some other way. ${ }^{25}$ I am skeptical about these worries, but nothing I have said shows they are mistaken. But whatever their merits might be, they are distinct from worries about self-determination.

\footnotetext{
Notes

Thanks to Allen Buchanan, Bill Edmundson, an anonymous referee, and an editor of this journal for critical but very constructive comments to earlier versions of this article. Above all, I would like to thank Kit Wellman who generously discussed the ideas in this article with me, and provided comments to multiple versions of this paper.

${ }^{1}$ For a related view, also discussed below, see Kershnar (2000).

${ }^{2}$ I say that states 'can' enjoy a right to self-determination to leave room for the possibility that not all states meet the normative criteria for this right.

${ }^{3}$ Other defenses for immigration restrictions cannot rely on such plausible starting points. For example, the argument that immigration may be restricted in order to protect local wages must appeal to the principle that protecting the financial interests of some can outweigh the freedom of millions of others, including those in great need. Such a principle is much less plausible. See Huemer (2010) for effective criticisms of this argument and others like it

${ }^{4}$ Below I introduce one minor caveat. However since it does not alter then general conclusion of the argument, the present formulation is not misleading.
} 
5 "The root notion of autonomy", Mele (2001, p. 3) points out, "(from autos and nomos) is self-rule or self-government."

${ }^{6}$ This rough description is relatively uncontroversial in the literature on autonomy. It is shared by those who find themselves on different sides of the historical versus non-historical autonomy debate on which I focus below. For useful overviews, see Christman (2011) and Buss (2008). Some insist on further (stronger) conditions, such as the ability to have done otherwise. I leave these issues aside since they do not impact the issues on which I focus here. I thank the editor for pressing me to clarify this.

${ }^{7}$ This loosely follows the accounts of self-determination given in Walzer (2006), Wellman (2012), and Altman and Wellman (2011). The account so far is similar to Daniel Philpott (1995) as well. In short: all these authors conceive of self-determination as morally important and all explicitly draw on the analogy with autonomy.

${ }^{8}$ See Buchanan (1999, pp. 17-8). Huemer (2010) adds that if states really were self-determining in the way voluntary associations are, it becomes unclear why, say, sexist or inegalitarian societies are unjust. Thus, insofar as one thinks that substantive demands of justice apply to states, they are not selfdetermining in the same way as free associations of individuals.

${ }^{9}$ The same appears in Altman \& Wellman (2011), which defines the right to self-determination as "irreducibly collective" (chs. 1 \& 2). It is unclear which understanding Walzer accepts. For example, when writing about intervention, he claims that "such an intervention would have violated the right of Nicaraguans as a group to shape their own political institutions and the right of individual Nicaraguans to live under institutions so shaped." (Walzer 1980, p. 220) However, given the troubles with the individualist view and the context of Walzer's argument about immigration, I believe a charitable interpretation attributes the collective view to him as well.

10 There may be other senses of self-determination. Perhaps a self-determining state is one in which the citizens can reasonably endorse the laws under which they live. Or perhaps we should abandon the analogy with autonomy altogether. Might such views support restrictive views about immigration? Perhaps, but they come at a cost. For one, they put significant distance between the sense of selfdetermination invoked in the context of immigration and the sense invoked in debates about democracy, sovereignty, and secession. This makes it unclear how we might, on such views, adjudicate the question whether the right to self-determination includes the right to control immigration. In any case, we can set these alternatives aside for now since they are different from the views invoked by the defenders of the right to restrict immigration. I thank an anonymous reviewer for pressing me to clarify this.

${ }^{11}$ Thus, invoking the individualist conception of self-determination, Kershnar (2010, p. 143) is mistaken when he says that " $[t] 0$ the extent that immigration threatens to change the nature of these institutions without the consent of the current members, it would follow that such immigration threatens to harm the citizens of the country by changing the character of the institutions to which the current citizens have consented. And this threat of harm justifies, other things being equal, preventing other persons from occupying a position where they could change the institutions in question."

12 Two points. First, Wellman uses the slightly different example of one state annexing the other. I choose the present example for two reasons: (a) it adequately expresses the intuitive appeal of Wellman's view, and (b) the example of annexation invites confusion (for reasons explained in note 16 below). Second, one might object to this view of self-determination as overly permissive. Perhaps, as Blake (2012) has argued, there are strong substantive limits to this right. In that case, Canada might not have a blanket freedom to resist the unwanted association with the US. I here do not pursue this line of thought. Instead, I will grant arguendo the strongest possible form of freedom of association and show that Wellman's argument still fails. I thank an editor for pressing me to clarify this. 
${ }^{13}$ In personal communication, Wellman has confirmed that the freedom of association argument accurately captures his view. (Mentioned with permission.) That said, Wellman's work also contains remarks that are compatible with a different argument. I discuss this in section 5 below.

${ }^{14}$ Of course this is not true of all immigrants. Many who seek entry do not care about joining the political community but merely seek a better place to live and (especially) work. Note, however, that in such cases it is even harder to describe immigrants as entering into an association with the state or community, making premise (2) of the freedom of association argument even more dubious. Wellman avoids this problem by arguing that immigrants should be granted full citizenship for reasons of political equality. I here follow Wellman's view for the sake of argument.

${ }^{15}$ Stronger still, Hillel Steiner (1992) argues that individual freedom of association implies not only that individual citizens have a right to each exclude foreigners, but also the right to invite them.

${ }^{16}$ And I can also explain why I refrained from using Wellman's own annexation example (see note 12 above). That example is wont to confuse. US annexation of Canada can violate the freedom of association of Canada understood along collective lines. Here is where the confusion comes in: since both cases (immigration and annexation) can be described as, in some sense, involving an act of incorporation, and since annexation would violate Canadian self-determination, one might think that that immigration too can violate collective self-determination even if the immigrant joins (and does not associate with) the state as a collective agent. But this is false. Annexation violates the selfdetermination of the collective agent because it is being incorporated. Not so for immigration. There, the collective agent is not itself being incorporated into some other body, but has somebody incorporated into it. To avoid this very confusing issue, I adopted the example of treaties in the text. (Of course, US annexation of Canada could also violate the freedom of association of Canadians understood along individualist lines. Canadian citizens, after all, would be forced into a political association they did not want. But this, we saw, will not help the argument for immigration restrictions.)

${ }^{17}$ This is a good thing too. The stakes are high with the freedom of association argument. Immigrants are not the only people who join the state and become new parts of its population. Newborn children become "associated" with the states in which they are born in just the same way. If a state's freedom of association gives it the right to reject immigrants on these grounds, it would seem that the state would also have a right to reject membership to babies.

${ }^{18}$ This case and others below are slightly modified versions of cases offered by Mele (2001) and Valdman (2010).

${ }^{19}$ For authors who take strongly different views on whether autonomy has a "historical" component, and if so what kind of component, see Buss (2005. 2012), Christman (1991), Dworkin (1976), Feinberg (1986), Fischer (2011), Frankfurt (1988), Haji and Cuypers (2004), Kane (1998), Mele (2001), and Valdman (2011). The issue is also discussed by various authors in Taylor (2005).

${ }^{20}$ See Smilansky (2002). Galen Strawson (2002, pp. 441-460) uses this implication to argue that the very concept of autonomy is incoherent.

${ }^{21}$ Two things deserve emphasis. First, it does not matter whether Dave and Beth in fact choose to act on, or to reject, their respective values. The relevant issue is their practical ability to shed. Second, it can happen that an agent can acquire values at $\mathrm{t} 2$ and $\mathrm{t} 3$ that make her unable to shed some value at $\mathrm{t} 4$ that she was able to shed at $\mathrm{t} 1$. Again, as long as the agent stood in the right relation to its new values at every step of the process, this need involve no loss of autonomy.

${ }^{22}$ Christman (1991) has proposed a different view that aims to achieve the same two goals. On his view, agents need not have accepted or endorsed the desire, but must accept or endorse the process by which it was acquired. This view is less promising to deliver the conclusions Walzer (and Wellman) want. The interesting suggestion of Christman's view is that the right to self-determination does not entitle groups to deny new members, but entitles them to require a certain process of joining. Since I am here interested in tracing the argument that is maximally promising for Walzer and Wellman, I focus on Mele 
instead. Another, and possibly more demanding, view is proposed by Haji and Cuypers (2004), who argue that the fact that a desire was implanted by an external force can be sufficient to debilitate autonomy because it is deviant from the "normal" or "baseline" manner of acquiring desires. However, I fail to see how the theorist of self-determination can appeal to this since it requires one to determine whether or not immigration is "normal" or "baseline" way for new members to come into the community. This seems to beg the very question we are trying to answer.

${ }^{23}$ Note that the same idea that the autonomous agent can shed values seems to promise a way of explaining why the right to self-determination does give groups the right to secede. Such secession may be analogous to the exercise of shedding values, the ability to which Mele sees as central to autonomy. This reinforces the conclusion above. For the same account of self-determination that allows us to make sense of the argument that self-determination supports secession at the same time tells against all but a highly limited right to restrict immigration.

${ }^{24}$ A real-world example might help. CASE 4 is loosely based on the Free State Project. The project is described on its website (http://freestateproject.org/) as "an effort to recruit 20,000 liberty-loving people to move to New Hampshire." Projects like this could violate self-determination if the conditions in the text are satisfied. That is, should (a) the Project's participants take over New Hampshire's political process, (b) the state's population not be able to resist this takeover through normal democratic means, and (c) the state's population not have chosen to allow such a takeover, then New Hampshire's collective self-determination might become compromised. Two things deserve emphasis. First, these are necessary conditions and may not be sufficient. Second, in fairness to the Free State Project, the Project's website explicitly states that its purpose is not a takeover of New Hampshire politics. Instead, it has selected the state for its already existing policies (which it deems liberty friendly).

${ }^{25}$ I thank an editor and an anonymous referee for these suggestions.

\section{References}

Altman, Andrew, and Wellman, Christopher H. (2011) A Liberal Theory of International Justice. Reprint. Oxford University Press.

Blake, Michael. (2012) Immigration, Association, and Antidiscrimination. Ethics 122: 748-762

Buchanan, Allen. (1999) Democracy and Secession. In ed.Moore, M. (ed.) National Self-Determination and Secession. Oxford University Press, 1999, pp. 17-8.

Buss, Sarah. (2005) Valuing Autonomy and Respecting Persons: Manipulation, Seduction, and the Basis of Moral Constraints. Ethics 115: 195-235

Buss, Sarah. (2008) Personal Autonomy. The Stanford Encyclopedia of Philosophy. Edward N. Zalta (ed.)

Buss, Sarah. (2012) Autonomous Action: Self-Determination in the Passive Mode. Ethics 122: 647-691

Christman, John. (1991) Autonomy and Personal History. Canadian Journal of Philosophy 21: 1-24

Christman, John. (2011) Autonomy in Moral and Political Philosophy. The Stanford Encyclopedia of Philosophy. Edward N. Zalta (ed.)

Dworkin, Gerald. (1976) Autonomy and Behavior Control. The Hastings Center Report 6

Feinberg, Joel. (1989) Harm to Self. 1st Printing 1986. Oxford University Press

Fine, Sarah. (2010) Freedom of Association Is Not the Answer. Ethics 120: 338-356

Fischer, John M. (2011) Deep Control: Essays on Free Will and Value. Oxford University Press

Frankfurt, Harry G. (1988) The Importance of What We Care About: Philosophical Essays. Cambridge University Press

Haji, Ishtiyaque, and Stefaan E. Cuypers. (2004) Moral Responsibility and the Problem of Manipulation Reconsidered. International Journal of Philosophical Studies 12: 439-464

Huemer, Michael. (2010) Is There a Right to Immigrate? Social Theory and Practice 36: 429-461

Kane, Robert. (1998) The Significance of Free Will. Oxford University Press 
Kershnar, Stephen (2000) There Is No Moral Right to Immigrate to the United States, Public Affairs Quarterly 14: 141-58

Mele, Alfred R. (2001) Autonomous Agents: From Self-Control to Autonomy. Oxford University Press Philpott, Daniel. (1995) In Defense of Self-Determination. Ethics 105): 352-385

Smilansky, Saul. (2002) Free Will and Illusion. Oxford University Press

Steiner, Hillel. (1992) Libertarianism and the Transnational Migration of People. In Barry, Brian and Goodin, Robert E. (eds.). Free Movement: Ethical issues in the Transnational Migration of People and of Money. University Park

Strawson, Galen. (2002) The Bounds of Freedom. In Kane, Robert (ed.) The Oxford Handbook of Free Will. Oxford University Press, pp. 441-460

Taylor, James Stacey, (ed.) (2005) Personal Autonomy: New Essays on Personal Autonomy and Its Role in Contemporary Moral Philosophy. Cambridge University Press

Valdman, Mikhail. (2010) Autonomy, History, and the Origins of Our Desires. Journal of Moral Philosophy 8: 415-434

Waldron, Jeremy. (2010) Two Conceptions of Self-Determination. In Besson, S. and Tasioulas, J. (eds.) The Philosophy of International Law. Oxford University Press

Walzer, Michael. (1980) The Moral Standing of States: A Response to Four Critics. Philosophy \& Public Affairs 9: 209-229.

Walzer, Michael. (1984) Spheres Of Justice: A Defense Of Pluralism And Equality. Basic Books

Walzer, Michael. (1993) Exclusion, Injustice, and the Democratic State. Dissent 40: 55-64

Walzer, Michael. (2006) Just And Unjust Wars: A Moral Argument With Historical Illustrations. 4th ed. Basic Books

Wellman, Christopher H. (2005) A Theory of Secession. Cambridge University Press

Wellman, Christopher H. (2008) Immigration and Freedom of Association. Ethics 119: 109-141.

Wellman, Christopher H. and Cole, P. (2011) Debating the Ethics of Immigration: Is There a Right to $\beta$ Exclude? Oxford University Press

\section{About the author}

Bas van der Vossen is assistant professor in philosophy at UNC Greensboro. His research

interests are in political philosophy. He has published in this journal before as well as in journals

such as the Journal of Political Philosophy, Law and Philosophy, the Oxford Journal of Legal

Studies, and Political Studies. 